REVISTA CHILENA DE LITERATURA

Abril 2010, Número 76, 27 - 42

\title{
NOVELAS-FOLLETÍN Y LA AUTORÍA FEMENINA EN LA SEGUNDA MITAD DEL SIGLO XIX EN CHILE
}

\author{
Carol Arcos \\ Universidad de Chile \\ arcosce@gmail.com
}

RESUMEN / ABSTRACT

Este trabajo busca poner en relieve el problema de la autoría femenina en la segunda mitad del siglo XIX en Chile a través de las estrategias de publicación y géneros del discurso literario que privilegian las mujeres escritoras, planteando, en tal sentido, la novela-folletín como un género que permite proveer a las escritoras de función-autor; esto, además, bajo la consideración de un proceso mayor como es el surgimiento de un espacio de opinión pública y la construcción de un incipiente campo cultural/intelectual.

Palabras clave: revistas y periódicos, novela-folletín, autoría femenina, Chile, siglo XIX.

This paper seeks to highlight the problem of female authorship in the second half of the nineteenth century in Chile, considering the publication strategies and the genres of literary discourse privileged by women writers. In this context, the feuilleton-novel is seen as a genre that allowed writers to provide the author-function, within the larger process of emergence of a public space and the construction of an incipient cultural/intellectual field.

KEY WORDS: Magazines and newspapers, novel-feuilleton, female authorship, Chile, 19th century. 
En nuestro número de hoy comenzamos la publicación de una novelita debida a la pluma de una joven escritora de San Bernardo, no desconocida en la república de las letras. Esa obra ha sido compuesta expresamente para las lectoras de LA FAMILIA, y nos alienta la confianza de que los más sinceros aplausos vendrán á estimular los trabajos de nuestra gentil colaboradora. Acompaña el folletín un grabado en madera, original que representará a la heroína de la narración ${ }^{1}$.

Proponemos este trabajo a modo de nota, pues su carácter es eminentemente exploratorio; en él buscamos dar cuenta de un aspecto poco relevado por la historiografía literaria en Chile como es la novela-folletín, además de plantear este género discursivo como una de las estrategias y prácticas de configuración de una/s autoría/s femenina/s a partir de la segunda mitad del siglo XIX. Esto bajo la consideración, en primer lugar, de un proceso mayor como es la emergencia de un espacio de opinión pública y la construcción de un incipiente campo cultural/intelectual; para luego comprender y situar el comienzo de una prensa de mujeres, territorialidad en la que se despliegan y modelan autorías femeninas, atendiendo, de igual modo, al proceso de formación de un público lector.

Preguntas/problemas tales como: ¿cómo ingresan y/o se presentan las mujeres, la construcción de determinadas figuras autoriales femeninas y la representación de las lectoras en el proceso de conformación del campo literario en Chile?, ¿qué trayectorias y estrategias utilizan las mujeres escritoras para "autorizar" sus discursos?, ¿qué géneros del discurso literario prefieren o asumen con el fin de lograr legitimidad dentro del campo?, ¿qué recepción tuvieron los textos publicados por mujeres en la prensa y a qué público se dirigían?; entre otras, son las que intentaremos tramar a lo largo de este trabajo. Nuestro enfoque se limitará a una perspectiva panorámica, buscando situar un problema y, por lo tanto, no nos detendremos en tal o cual texto y escritora en particular, esperando poder hacerlo en una futura ocasión.

1 Redacción. La Familia, periódico quincenal ilustrado, de literatura, ciencias, artes, modas y conocimientos útiles. Santiago: Imprenta Cervantes. 1/2 (1 de septiembre de 1890). 


\section{MUJERES ESCRITORAS EN EL ESPACIO PÚBLICO DE LA OPINIÓN}

La relativa autonomía del campo literario $^{2}$ en Chile no arriba sino hasta las últimas décadas del siglo XIX con el advenimiento del naturalismo y el modernismo, momento en que la literatura rompe con la dependencia directa que tenía con el dominio de lo político, con el campo de poder, y asume un carácter más especializado respecto de otras producciones simbólicas. Junto con este proceso de especialización se aprecia la profesionalización del escritor y la emergencia de un grupo significativo de intelectuales de claro perfil mesocrático; ahora bien, una de las características que mejor escenifica las transformaciones que se sucederán en la vuelta de siglo tiene que ver con el desplazamiento semántico que opera en el término mismo de lo literario, el que connotará cada vez más a producciones de imaginación y asumirá la preeminencia estética como parte de un concepto de la modernidad burguesa, dejando así de referir al sentido hegemónico dieciochesco e ilustrado de utilidad pública que abarcaba un campo semántico mucho más amplio y congregaba en su dinámica no solo a las Bellas Letras, sino también y fundamentalmente a todos los libros impresos (desde las ciencias humanas a las naturales y exactas, la economía, la política, la filosofía, la religión y la moral), un concepto que se encontraba más vinculado a littera, es decir, relacionado con el arte de escribir y leer.

Se subentiende, por lo tanto, que en el Chile de mediados del siglo XIX el espacio cultural entrecruza, a la luz de la construcción intelectual de la nación signada por el liberalismo, los distintos ámbitos: político, literario, historiográfico y social, patentizándose estos como territorios de enunciación ancilares ${ }^{3}$. Bajo este panorama, las revistas y periódicos se

2 Entendiendo por campo cultural y/o literario lo precisado por Pierre Bourdieu (1990 y 2002) desde el terreno de la sociología de la producción cultural, es decir, un espacio de producción de bienes simbólicos y de un sistema de fuerzas en el que se despliega una competencia por la legitimidad cultural, una lucha por la hegemonía. El campo no es un medio, es decir, un universo de relaciones personales entre los artistas o los escritores, sino un campo de fuerzas que actúa sobre todos los que entran en ese espacio y de maneras diferentes según la posición que ellos ocupan en él, a la vez de un campo de luchas que procura transformar ese campo de fuerzas. Además, en relación con el campo literario en Chile, véase el artículo pionero de Gonzalo Catalán (67-175).

3 En el sentido que propone Alfonso Reyes en El Deslinde (1988), es decir, una literatura al servicio de, en este momento al servicio de la construcción de la nación. Por lo tanto, lo que se busca explicitar es el concepto utilitario de lo literario. 
constituyen como la estrategia textual de publicación privilegiada y más distintiva -considerando, por lo demás, que en este momento la actividad editorial y la imprenta en Chile, no es aún sostenida ni constante en relación con la publicación de libros- utilizada por la élite letrada en el siglo XIX. Se trata de una prensa, sobre todo en la primera mitad del siglo, iluminista con un afán didáctico - en esta podemos distinguir, al menos, dos momentos, una primera marcada por el discurso judicial-deliberativo del proceso de independencia de la metrópolis ${ }^{4} \mathrm{y}$ luego una prensa signada por el movimiento del 42 y sus debates ${ }^{5}$-, para dar paso hacia 1850 en adelante a una de tipo más especializada que se vincula al proceso de autonomización del campo cultural/intelectual.

En esta segunda o tercera oleada de papeles periódicos se publican novelas-folletín, crónicas, cartas, ensayos, reseñas de libros, avisos de variada índole, traducciones de obras literarias sobre todo francesas, poesías, cuadros de costumbres, entre otros géneros discursivos. Por otra parte, a través de esta prensa se va configurando un pensamiento crítico que pretende romper con el pasado colonial, buscando una nueva forma de pensar lo político; dichas publicaciones se constituyen en un gesto moderno que permitirá ir rompiendo lentamente con la sociedad censitaria o, más bien, con la ciudad escrituraria, al ser distribuidos entre capas de población cada vez más amplias.

Desde las páginas de estos periódicos, a lo largo del siglo, sujetos de la talla de Camilo Henríquez, Andrés Bello, J. V. Lastarria, Francisco Bilbao, D. F. Sarmiento, entre muchos otros, desarrollarán una ensayística en torno a la identidad y la construcción de las naciones republicanas. Ahora bien, es también en la segunda mitad de este siglo que se observa el surgimiento de mujeres autoras en Chile y América Latina a la luz del despliegue de la prensa, que aun cuando no forman un grupo significativo en los campos

4 Entre estos periódicos encontramos: La Aurora de Chile (1813), El Monitor Araucano (1813), El Argos de Chile (1818), El Sol (1818), El Duende de Santiago (1818), El Telégrafo (1819), La Miscelánea Chilena (1822), El Mercurio de Chile (1822), El Tizón Republicano (1823), El Clamor de la Patria (1823), El Mercurio de Valparaíso (1827), entre otros.

5 A partir de este importante momento en relación con la publicación de revistas y periódicos que atienden a un despliegue de las ciencias y la literatura, encontramos títulos tales como: Revista de Valparaíso (1842), El Museo de ambas Américas (1842), El Semanario de Santiago (1842), El Crepúsculo (1843), El Mosaico (1846), Revista de Santiago (1848), entre otras de más corta duración. 
literarios en constitución, sí escenifican el importante pasaje de la lectura a la autoría femenina pública ${ }^{6}$.

En Chile, la libertad de imprenta había sido oficializada desde los primeros decretos constitucionales en los albores de la república, no existiendo, además, impedimentos legales para que las mujeres publicaran. Sin embargo, ese discurso oficial omitía la reglamentación de prácticas que eran consideradas, por así decirlo, improbables; esto debido, quizás, a que para los legisladores de la nueva república era, en ese momento, más importante estructurar el sistema político de gobierno que clarificar las situaciones entre los y las civiles. Es solo a partir de la segunda mitad del siglo, entonces, a partir de la década del 60 que comenzaron a aparecer, de forma muy tímida aún, escritos firmados con nombres femeninos dentro de periódicos y revistas literarias y culturales de la época; por ejemplo, en el segundo período de existencia de la Revista de Santiago (1872-73) -órgano literario que contaba con la participación estable de Diego Barros Arana, Benjamín Vicuña Mackenna, José Victorino Lastarria, Miguel Luis Amunátegui, Eugenio María de Hostos- se publica el connotado prólogo-ensayo que escribiera Martina Barros Borgoño (sobrina de Diego Barros Arana) al libro de Stuart Mill, La esclavitud de la mujer ${ }^{7}$, y algunas poesías de Rosario Orrego Carvallo, quien además publica en la revista La Semana, dirigida por los hermanos Domingo y Justo Arteaga Alemparte, Sud-América de Santiago y La Revista del Pacifico de Valparaíso. Es también a partir de dicha fecha que comienzan a aparecer las primeras publicaciones periódicas de mujeres o atribuidas a ellas. Atribuidas en el caso, por ejemplo, del periódico semanal El Eco de las Señoras de Santiago, que se publicó desde el 13 de julio al 7 de octubre de 1865, por medio de la imprenta El Independiente perteneciente a sectores del Partido Conservador,

6 Entre ellas podemos nombrar rápidamente a: La Condesa de Merlín (1789-1852) y Gertrudis Gómez de Avellaneda (1814-1873) en Cuba; Dionisia de Faria Rocha (***), María Firmina dos Reis (1825-1917), María Benedicta Câmara Bormann (***) y Julia López de Almeida (***) en Brasil; Manuela Sáenz (1795-1856) en Ecuador; Mariquita Sánchez (17861868), Eduarda Mansilla (1838-1892), Rosa Guerra (***-1864), Juana Manuela Gorriti (18161892) y Juana Manso (1820-1875) en Argentina; Mercedes Cabello de Carbonera (1845-1909) y Clorinda Matto de Turner (1852-1909) en Perú; Adela Zamudio (1854-1928) en Bolivia; Mercedes Marín del Solar (1804-1866), Quiteria Vargas (1838-1886), Carmen Arriagada (1807-1900) y Rosario Orrego de Uribe (1834-1879) en Chile; entre otras, componen un corpus de mujeres autoras que incursionan en la palabra escrita, privada y pública, a través de diversos géneros del discurso.

7 En 2009, Alejandra Castillo publica este prólogo por la editorial Palinodia. 
alcanzando un tiraje de 12 números y que circuló en Santiago y Valparaíso; surge, según indica en su prospecto titulado "A nuestras compatriotas", a raíz del debate en torno a la reforma del artículo $5^{\circ}$ de la Constitución de 1833, el cual trataba acerca de la religión del Estado y establecía el culto público exclusivo de la religión católica. Este periódico, por lo tanto, se presenta como bastión de defensa de dicho artículo y contradiscurso con respecto a la libertad de culto. Si eran o no mujeres quienes efectivamente escribían dicho órgano -en un momento álgido de los procesos de secularización del Estado y de su relación con el catolicismo y la Iglesia- fue material de polémica en su contemporaneidad y aún hoy ${ }^{8}$.

Una segunda publicación periódica de importancia en este período es la Revista de Valparaíso, órgano publicado desde 1873 a 1875 bajo la dirección de Rosario Orrego Castañeda (de Uribe) y mediante la Imprenta de "El Mercurio". Su importancia radica en el hecho de que a partir de ella es posible distinguir un nuevo momento en el ejercicio de la opinión pública por parte de las mujeres y la puesta en escena de una autoría descubierta, es decir, una publicación exhibida dada por la exposición del nombre legal de las autoras.

Este gesto sostenido y constante de publicación femenina no se presenta, de acuerdo a nuestras indagaciones con respecto a prensa de mujeres en este momento, hasta 1890 año en que sale a la luz La Familia, periódico quincenal ilustrado, de literatura, ciencias, artes, modas y conocimientos útiles. Desde el 15 de agosto de 1890 al 12 de diciembre de 1892 se publica este periódico bajo la dirección de Celeste L. de Cruz-Coke, a través de la Imprenta Cervantes, contando con 94 números; aun cuando explícitamente se proponga en el editorial del primer número titulado "Nuestra primera palabra" que es una publicación dirigida al conjunto de la familia, al mismo tiempo que construye una idea acerca de ella, pareciera más bien de acuerdo a los paratextos ${ }^{9}$ y marcas textuales, que apelaba de forma exclusiva a lectoras. Por otra parte, un rasgo diferenciador e innovador en relación con

8 Debate que ya ha escenificado la historiadora Ana María Stuven en su artículo "El Eco de las Señoras de Santiago. El surgimiento de una opinión pública femenina" (303-326). También encontramos referencia a esta polémica en la tesis de Licenciatura en Historia de María José Zaldívar (2002).

9 En esto sigo además de las propuestas chartianas, lo precisado por Gérard Genette, es decir, el paratexto será todo aquello por lo cual el texto se hace libro (pero también, agregaremos, revista, periódico y en más amplio término, impreso), y se propone como tal a 
los anteriores órganos periódicos de mujeres es la presencia de ilustraciones o "grabados", como se les llamaba en La Familia, que representaban a personajes importantes del campo político y/o militar chileno y extranjero, mujeres exponentes de las artes y las letras, edificios públicos destacados de Estados Unidos y Europa, entre otros; éstos eran detalladamente descritos en la sección "Nuestros grabados".

Ahora bien, debemos tener en cuenta que la emergencia de la prensa periódica no solo difundió saberes y promovió representaciones, sino también como práctica ayudó a forjar la opinión pública, pues la circulación de estos impresos y las prácticas de lectura, que difunden una nueva urbanidad en las nacientes repúblicas, son nodales al momento de pensar en el surgimiento de un espacio crítico, de una "esfera pública política", en términos de Jürgen Habermas (1981), frente a la autoridad del Estado; proceso que, al menos en Chile, no se patentiza antes del siglo XIX. En tal sentido, Roger Chartier (2002) ha precisado la esfera pública política como un espacio de debate donde las personas privadas hacen un uso público de su razón, en igualdad y sin que ningún límite pueda ser puesto al ejercicio de su juicio. Esta esfera pública habría de evidenciarse en los salones, cafés, clubes, sociedades literarias, logias masónicas y hacerse posible gracias a la circulación multiplicada de lo escrito ${ }^{10}$.

Es pues en este espacio público de la opinión -no olvidando además que es justamente en este siglo en que las esferas separadas de lo público y lo privado comienzan a patentizarse de modo más prominente en los Estadosnación en ciernes- que debemos comprender la manifestación inicial de la autoría de mujeres desplegada en la prensa. Por autoría entenderemos - a partir de la consideración de conocidos trabajos que han tratado desde diversas perspectivas los problemas inherentes a la autoría en general ${ }^{11}$ - no solo la

sus lectores. El paratexto se compone de un conjunto heteróclito de prácticas y discursos de toda especie que se agrupan en torno a una convergencia de efectos ( 7 y 8).

10 Además, es importante señalar la notabilidad que espacios como los salones a lo largo del siglo XIX y las tertulias y círculos de lectura a comienzos de XX adquieren en relación con la participación en ellos de mujeres y el fundamental pasaje de la lectura y la oralidad a la autoría femenina.

11 En tal sentido, además de los trabajos que citaremos a continuación, son importantes las investigaciones de Graciela Batticuore en Argentina y Juan Poblete para el caso chileno. También la Dra. Darcie Doll prontamente publicará un libro en relación con el problema de la autoría femenina y la crítica literaria en Chile en la vuelta del siglo XIX al XX. 
atribución de un nombre, sino las redes de poder/saber en las que se traman ciertas rúbricas que "autorizan" o "legitiman" la atribución o autoridad de la escritura. Por lo tanto, la autoría tendrá que ver con las formas en que se inscribe el sujeto en el discurso, su concreción en el espacio público a través de ciertas figuras, las estrategias u operatorias que utiliza para hacerlo, así como también la articulación de particulares retóricas en su textualidad.

Desde la perspectiva de Michel Foucault y su noción de función-autor como construcción discursiva, la autoría es dispuesta como una función propia del discurso y por lo tanto no atribuible a un individuo empírico, es decir, el autor no existiría fuera de su práctica discursiva:

[...] el nombre de autor no va, como el nombre propio, del interior del discurso al individuo real y exterior que lo ha producido, sino que corre, en algún modo, en el límite de los textos, que los recorta, que sigue sus aristas, que manifiesta su modo de ser o, por lo menos, lo caracteriza. Manifiesta el acontecimiento de un cierto conjunto de discursos, y se refiere al estatuto de este discurso en el interior de una sociedad y en el interior de la cultura (338).

Así, se podría argumentar que existen en una determinada época y lugar un cierto número de discursos que están provistos de función-autor, mientras que otros están desprovistos de ella; la función-autor, por lo tanto, es el modo de circulación y funcionamiento de ciertos discursos "autorizados" en el interior de una sociedad. Vista, desde este planteamiento, la autoría femenina decimonónica ciertamente se presenta de modo conflictivo, pues la noción autor como sanción de discursos públicos y no meramente como atribución de un nombre está cruzada por diversas variables, entre las que encontramos la diferencia de género-sexual (y también étnicas, clasistas, etarias, entre otras) - por lo tanto, a diferencia de Foucault sí creemos en la positividad de la autoría- y en las que operan criterios que autorizan el ingreso o exclusión de ciertos discursos y figuras autoriales.

Ahora bien, es importante precisar que en la genealogía de la construcción moderna de la función-autor, desde la perspectiva foucaultiana, esta no se limitará al momento en que se ha instaurado un régimen de propiedad para los textos, es decir, cuando se han sancionado leyes sobre los derechos de autor, las relaciones autores y editores, etc. ${ }^{12}$, sino que habría sido el régimen de

12 Leyes que en Chile se instalan desde un momento temprano en la Constitución de 1833; en su artículo 152 se establecía que todo autor tendría la propiedad exclusiva sobre su 
apropiación penal el momento fundador de dicha función. Esto es: surge en la medida en que el autor podía ser castigado si sus discursos eran transgresores, vinculándose, por tanto, al ejercicio del poder por parte de una autoridad que tiene el derecho de censurar. En tal sentido, en las colonias de la América hispana las leyes de Indias habrían provisto el sistema de privilegio regio sobre cualquier obra, dando el consentimiento o no a su publicación o lectura de acuerdo a los dictámenes del monarca o el Santo Oficio ${ }^{13}$. La función-autor, siguiendo lo propuesto por Roger Chartier en El orden de los libros, tanto desde la perspectiva que la vincula con las censuras de la Iglesia o del Estado como desde la que la asocia a la propiedad intelectual en sentido moderno burgués, se inscribe plenamente en el marco de la cultura impresa (61). Es pues la circulación de impresos entre un público cada vez más amplio lo que comienza a desafiar a la autoridad y crea una cadena de intervenciones y mediaciones (copistas, editores, tipógrafos, etc.) entre autor y lector.

Durante la segunda mitad del siglo XIX, en Chile la reglamentación legal indudablemente autoriza y permite ciertas figuras autoriales y no otras en un espacio cultural marcado sexo-genéricamente y privilegiadamente masculino, pero al vincular la producción textual con sujetos femeninos, esta perspectiva no agota los problemas en torno a cómo las mujeres y su posible construcción de autoría presenta una entrada dificultosa y compleja. Pues bien, creemos que la óptica señalada nos permite comprender la formación moderna de la figura del autor y problematizar los criterios que autorizan la escritura, pero la cuestión de la escritura pública de mujeres no solo se emparienta con la legitimación legal o propiedad intelectual de un texto (que en caso de existir lo es por medio del tutelaje masculino: padres, esposos o hermanos), sino también con un imaginario moralizante que sanciona fuera del ámbito estrictamente legal y se vincula a lo cotidiano, es decir, la construcción de autoría por parte de las mujeres estará inscrita en una

producción por el tiempo que le concediere la ley. Luego, a partir de esta disposición, se dicta en 1834 la Ley de Propiedad Literaria y Artística.

13 Aunque legalmente existían tres clases de obras vetadas para el traspaso y publicación en el Nuevo Mundo: textos de imaginación literaria, textos considerados herejes por el Tribunal del Santo Oficio y textos de perfil político contrarios al regalismo y a la monarquía; la sanción a través de medidas legales no se observó a cabalidad y solo al finalizar el siglo XVIII -como parte de las reformas borbónicas- emerge una preocupación real y una mayor sanción sobre la posesión, publicación o lectura de libros prohibidos, sobre todo de aquellos que tenían vínculo con las ideas políticas, liberales y/o revolucionarias, que comenzaban a eclosionar en Europa. 
red de formas de representación y categorías organizadoras de lo "real", en las que la honra femenina ponía en juego el honor familiar. En efecto, este honor se constituye como un importante discurso hegemónico de control y vigilancia de los comportamientos y cuerpos de hombres y mujeres en el siglo XIX, ya que las familias criollas se habían conformado siguiendo los parámetros jurídicos, sociales y religiosos de la metrópoli española, siendo la familia católica (indisoluble, monogámica, portadora de la fidelidad sexual de las mujeres y responsabilidad del padre hacia la prole) una de las marcas culturales más significativas para la élite como signo de estatus y espacio en donde se establecía el consenso acerca del "orden natural de las cosas". Así, una escritora que publica pone en juego la moral familiar al agrietar el ideal de la mujer doméstica; en torno a esto Graciela Batticuore ha puntualizado:

Puesto que el honor de una mujer afecta por entonces directamente la moral de su familia (y esto es así desde la Colonia), una escritora que publica pone inevitablemente en juego esa moral. Este es uno de los motivos principales por el que la figura de la autora resulta casi siempre inquietante e incluso a veces indeseable. O bien obliga a una cantidad de justificaciones y de recomendaciones por parte de aquéllos que apoyan o promueven su obra, cada vez que el texto firmado por una mujer sale a la luz pública (204).

Por lo tanto, la construcción de autoría femenina en el momento que nos atañe se presentará a través de diversas modalidades y recurrirá a distintas estrategias retóricas para concretizarse en el espacio público y circulación de impresos, bajo este imaginario moralizante que sanciona fuera de la reglamentación legal.

\section{FOLLETINES: UNA ESTRATEGIA PARA LA AUTORÍA}

La prensa es el principal espacio de publicación para los autores y autoras en el siglo XIX; es a través de ella que comienzan a circular las obras de escritores nacionales e internacionales (ante todo franceses, ingleses $\mathrm{y}$, en menor medida, españoles) en la sociedad urbana. Del mismo modo, en ella se publican las primeras obras literarias que comenzaban a diseñar un nuevo panorama en relación con el campo cultural en Chile y el concepto de lo literario, todo ello asociado a una lenta pero sostenida profesionalización del literato y publicista; parte fundamental en este proceso es la presencia 
de la novela-folletín. Muy extensa resulta la publicación de folletines en los periódicos y revistas del siglo XIX; el primero en comenzar a publicar folletines literarios fue el periódico El Progreso (1842-1853). En él se dieron a conocer autores extranjeros tan connotados como Victor Hugo, Lord Byron, Alejandro Dumas (padre), George Sand, y también se publica Facundo de Domingo Faustino Sarmiento. Asimismo, es en El Ferrocarril (1855-1900) donde se publica una de las obras más importantes del romanticismo como es Los miserables de Victor Hugo (1863); pero también obras fundamentales para el realismo chileno como Martín Rivas, La venganza, Un drama en el campo, El ideal de un calavera de Alberto Blest Gana, en el periódico La voz de Chile (1862-1864).

Resulta casi interminable la lista de novelas-folletín que se publican desde 1840 a 1890 en la prensa, ya sea como novelas por entregas u obras que ya terminadas eran publicadas por capítulos, en la parte inferior de las planas del impreso regularmente. Estas novelas-folletín contribuyeron de forma decisiva en la formación de un nuevo público lector en el proceso mismo de las políticas de alfabetización en el Chile de mediados de siglo, a la vez que forman parte de la, por así llamarla, pedagogía política de las élites para difundir las nuevas sensibilidades y los ideales de civilidad que estaban emergiendo en el campo ideológico, además de participar en el proceso de subjetivización de la modernidad burguesa. En este último sentido, Susana Zanetti ha precisado que:

[...] un sector de las élites confiaba en que los folletines (y las novelas) podían lograr mayores y más amplios efectos en el conjunto de la población alfabeta y urbana que otros discursos que se proponían aleccionar acerca de los modelos de sociabilidad y de familia convenientes para flamantes naciones que cumplían o intentaban cumplir una rápida modernización y consolidación del estado nacional (107-108).

Los folletines como el espacio en que surge el género novela en Chile y América Latina, por lo tanto, iban diseñando lectores y lectoras ideales con un fin didáctico que buscaba dirigir las conductas tanto privadas como públicas.

Es importante advertir que los papeles periódicos con los que hemos trabajado (ver bibliografía) se dirigen a un público ilustrado y de élite, esto de acuerdo a los paratextos - es decir, los formatos, portada, anexos, composición de las tiradas, los nombres de autor/a, los títulos, las dedicatorias, los epígrafes, las ilustraciones, entre otros-y las marcas textuales -enunciados 
verbales que significan un real, es decir, lo que constituyen como referente fuera de sí mismo, las reglas de escritura particulares al género que señalan los diferentes textos que componen las revistas y periódicos y los modelos discursivos operantes- que se ocupan para apelar a él. Ahora bien, ese público al que se alude en las novelas-folletines será principalmente femenino y, por otra parte, es importante señalar que solo a partir de las últimas décadas del siglo los lectores y lectoras figurados tendrán un perfil más mesocrático.

Mientras en Europa existió una alianza entre prensa popular y novelasfolletín ${ }^{14}$, en el Chile decimonónico este género se presentó, como queda dicho, ante todo en las producciones escriturales de la oligarquía (comprendiendo a esta élite como un grupo heterogéneo), pues así como ha enfatizado Manuel Vicuña:

[...] los vínculos de reciprocidad entre patrones e inquilinos y sirvientes, entre gobernantes y gobernados, se tornaron irrelevantes; las nuevas formas de sociabilidad imperantes y los estilos de vida cosmopolitas, concedían protagonismo a los aristócratas con radical exclusión de otros sectores sociales, los que a lo sumo intervenían a título de funcionales proveedores de servicios, nunca en calidad de interlocutores reales (17).

Desde esta perspectiva es observable la imbricada relación entre campo cultural y campo de poder, en la que los avatares de la literatura de folletín se expresa. La mayoría de estas novelas erigen como temáticas principales a la familia oligárquico-burguesa como sinécdoque de la nación y refugio de un espacio privado, en un esfuerzo por replantear las relaciones sociales y de género, es decir, se configuran desde un carácter edificante (las mujeres signan el orden moral y espiritual, también son presentadas como madres letradas que tienen como fin aportar en la ilustración de la nación a través de la familia), y además escenifican un cambio en la sensibilidad en relación con el amor como una experiencia cada vez más importante en los vínculos matrimoniales. Tal como ha discernido Beatriz Sarlo (1985) para las novelas semanales de comienzos del siglo XX en Argentina, estos folletines son textos de la felicidad, pues el amor se erige como la materia narrativa más interesante, diseñando un imperio de los sentimientos en donde el motor es

14 Al respecto véase, por ejemplo, para el caso español, el trabajo de Juan Ignacio Ferreras (1972). 
la subjetividad y el logro de un equilibrio amoroso que nunca es presentado como un espacio social o político por modificar radicalmente. Bajo este panorama, es que la educación sentimental a través del ofrecimiento de pautas de comportamiento y trato amoroso se convierte en uno de los fines cardinales de este tipo de literatura.

Como estrategia u operatoria de publicación de mujeres, estas novelas se presentan como uno de los géneros textuales más proclives para la "autorización" y conformación de una autoría femenina en la segunda mitad del siglo XIX. Si bien otros géneros del discurso literario permitían la circulación de figuras autoriales femeninas, como la poesía ${ }^{15}$ y las cartas, a partir de 1850 la novela es vista como la forma más adecuada para fijar el perfil de la literatura chilena (Subercaseaux, Historia de las ideas 136). En este momento aparece todavía la idea de la utilidad política y edificante de la novela; pero se comienza a patentizar una preocupación por las exigencias estéticas relativas a la composición de la obra y el tratamiento del tema desde un romanticismo y realismo de cuño liberal. Si bien esta supremacía de la novela para fijar una literatura nacional explica su cultivo y la conformación de trayectorias y tomas de posición de autores en la segunda mitad del siglo, no agota el significado que cobra el folletín para la construcción de sujetos de enunciación femeninos en el espacio público, ya que este género se perfilará como una literatura melodramática al exacerbar las pasiones, presentar una estructura reiterativa, personajes estereotipados, situaciones inverosímiles, utilización de lugares comunes y desenlaces consolatorios; a medida que avance el siglo, esta literatura comenzará a ser considerada como un género menor.

En el centro de estas novelas se encuentra la cuestión femenina como terreno propicio para hablar y educar los afectos; así, por ejemplo, en las novelas-folletín publicadas en el periódico La Familia encontramos títulos tales como "El novio de Elena", "María Luisa" y "Rosa de Abril"16, entre otros, que recrean tópicos ya clásicos en la literatura occidental, tales como el matrimonio entre desiguales y el desencuentro de los enamorados debido Marín.

15 Un caso emblemático, en tal sentido, es Mercedes Marín del Solar y Quiteria Varas

16 La primera novela-folletín es firmada por Juana Lind, mientras que la segunda, por De Bertall. La última habría sido publicada por la directora del periódico bajo el seudónimo de Lodoiska Maapaká, desde de su número 38 (noviembre de 1891) hasta el 82 (septiembre de 1892). 
a un destino ineluctable. Como "género literario de los afectos", la novelafolletín se liga, indudablemente, a la ideología de las esferas separadas y la domesticidad que fortalece discursos hegemónicos - provenientes desde el campo de la medicina, la política, la moral y la religión- en relación con el rol socio-cultural de las mujeres. Desde aquí también pensamos esta práctica escrituraria como una operatoria de entrada de las mujeres a la ciudad letrada decimonónica, pues es un tipo de escritura asociada a lo femenino y, por ende, "autoriza" el despliegue de una función-autor menos conflictiva con dicho discurso, permite la composición de autorías femeninas dadas ya sea bajo el seudónimo, anonimato o el nombre legal de las escritoras. En esta última dirección, Gérard Genette precisa con respecto a las figuras que permiten el nombre de autor que:

El nombre de autor puede $[\ldots]$ asumir tres condiciones principales [...]. O bien el autor "firma" con su nombre real (podemos suponer, sin conocer estadísticas, que es el caso más frecuente) o bien firma con un nombre falso, fingido o inventado: es el seudonimato; o no firma de ninguna manera, es el anonimato (38).

En el caso de las mujeres que publican novelas-folletín -entre ellas merecen especial mención Rosario Orrego de Uribe y Celeste L. de Cruz-Coke- en la segunda mitad del siglo XIX en Chile, el "nombre autor" responderá a elecciones que tienen que ver justamente con lo que precisábamos antes, es decir, con la preeminencia de un imaginario moralizante con el que deben "jugar" para componer una trayectoria de autoría que no disloque los discursos republicanos y patriarcales operantes.

\section{A MODO DE CIERRE}

Como anotábamos en un comienzo, este trabajo buscaba plantear un problema en torno a las estrategias de inserción de las mujeres escritoras en un campo cultural en constitución y signado por el arranque de un espacio de opinión pública. Creemos que uno de los géneros del discurso literario que permite la composición de autoría femenina, en la segunda mitad del siglo XIX, es la novela-folletín, pues éste otorga a las escritoras una cierta unidad de escritura y voluntad de estilo, es decir, posibilita la inscripción de, por así llamarlo, un foco de expresión manifiesto en cada una de las obras que se les asignan. Al contrario de lo que ocurre, por ejemplo, con la publicación de cartas en 
la prensa, ya que estas modelan una escritura ocasional que no evidencia, al menos en este momento en Chile, una toma de posición dentro del espacio cultural y una búsqueda de autoría dentro de los discursos que autorizan y legitiman lo escrito e impreso en el espacio público.

Por lo demás, la novela-folletín evidencia un correlato con la función otorgada a la novela realista por autores tales como José Victorino Lastarria, Joaquín Blest Gana y Alberto Blest Gana, esto es, el medio más adecuado para la investigación artística de los hechos sociales y el tipo de obra que ofrece mejores perspectivas para interesar a nuevos lectores y ampliar el mercado literario (Subercaseaux, Historia de las ideas 147), aun cuando los hechos que el folletín refiere y compone como lo real se circunscriban a los sentimientos y afectos. Consiguientemente, el género de la novela se presenta como una de las estrategias discursivas para componer función-autor y que en el caso de las mujeres posibilita un ingreso menos conflictivo en el espacio público no solo en relación con un imaginario moralizante y patriarcal, sino también con respecto a los propios discursos literarios que operan en ese momento y sus géneros.

Por último, creemos ${ }^{17}$ que uno de los problemas centrales en relación con la escritura de mujeres en el período radica en la construcción de una autoría y un discurso propio en los espacios público y privado moderno-burgueses. La escritura en estas autoras, a través de los diversos géneros discursivos que practican, se presenta como una práctica que posibilita un compromiso con el espacio público y patentiza la intención y necesidad de construirse un lugar en el campo intelectual. Para lograr legitimidad en el campo asumirán preferentemente algunos de los géneros del discurso literario como estrategias de publicación que permiten proveer a las escritoras de función-autor: en un primer momento (romanticismo/realismo), serán la novela-folletín y la poesía y, más tarde (naturalismo/modernismo), el ensayo y la crítica literaria, principalmente.

17 En esta última reflexión agradezco las conversaciones y el trabajo desarrollado con la Dra. Darcie Doll. 


\section{BIBLIOGRAFÍA}

Batticuore, Graciela. La mujer romántica. Lectoras, autoras y escritoras en la Argentina: 1830-1870. Buenos Aires: Edhasa, 2005.

Bourdieu,Pierre. "El campo literario. Prerrequisitos críticos y principios de método". Revista Criterios 25-28 (enero 1989-diciembre 1990): 20-42.

Campo de poder, campo intelectual. Itinerario de un concepto. Tucumán: Montressor, 2002.

Catalán, Gonzalo. “Antecedentes sobre la transformación del campo literario en Chile entre 1890 y 1920”. En José Joaquín Brunner y Gonzalo Catalán, Cinco estudios sobre cultura y sociedad. Chile: FLACSO, 1985. 67-175.

Chartier, Roger. El mundo como representación. Historia cultural: entre práctica y representación. España: Gedisa, 2002.

Entre poder y placer. Cultura escrita y literatura en la edad moderna. Madrid: Cátedra, 2000.

El orden de los libros. Lectores, autores, bibliotecas en Europa entre los siglos XIV y XVIII. España: Gedisa, 1996.

Ferreras, Juan Ignacio. La novela por entregas 1840-1900. España: Taurus, 1972.

Foucault, Michel. “Qué es un autor?” Entre filosofia y literatura. Obras esenciales, volumen I. España: Paidós Ibérica, 1999.

Genette, Gérard. Umbrales. México: Siglo XXI, 2001.

Habermas, Jürgen. Historia y crítica de la opinión pública. Barcelona: Gustavo Gilli, 1981.

La Familia, periódico semanal ilustrado de literatura, ciencias, artes, modas y conocimientos útiles. Santiago: Imprenta Cervantes, 1890-1892.

Reyes, Alfonso. El deslinde, prolegómenos a la teoría literaria. México: FCE, 1988.

Sarlo, Beatriz. El imperio de los sentimientos. Narraciones de circulación en la Argentina (1917-1927). Argentina: Catálogos editora, 1985.

Silva Castro, Raúl. Panorama literario de Chile. Santiago: Universitaria, 1961.

Stuven, Ana María. "El Eco de las Señoras de Santiago. El surgimiento de una opinión pública femenina". Lo público y lo privado en la historia americana. Chile: Fundación Mario Góngora, 2000. 303-326.

Subercaseaux, Bernardo. Historia de las ideas y de la cultura en Chile. Tomo I: Sociedad y cultura liberal en el siglo XIX: J.V. Lastarria. Santiago: Universitaria, 1997.

Historia del libro en Chile (Alma y Cuerpo). Santiago: LOM, 2000.

Vicuña, Manuel. La belle époque chilena. Alta sociedad y mujeres de elite en el cambio de siglo. Santiago: Sudamericana chilena, 2001.

Zaldívar, María José. "Participación femenina en Chile durante la segunda mitad del siglo XIX a través del ejercicio de las libertades de imprenta, de enseñanza y de asociación". Tesis de Licenciatura en Historia. Pontificia Universidad Católica de Chile, 2002.

Zanetti, Susana. La dorada garra de la lectura. Lectoras y lectores de novela en América Latina. Argentina: Beatriz Viterbo Editora, 2002. 